\title{
Study on the corrosion resistance of sisal fiber concrete in marine environment
}

\author{
Huiming Bao ${ }^{1} \mathbb{D} \cdot$ Hanqing Meng ${ }^{1} \cdot$ Wei You $^{2} \cdot$ Feng Qin $^{3}$
}

Received: 11 June 2019 / Accepted: 22 October 2019 / Published online: 6 November 2019

(c) Springer Nature Switzerland AG 2019

\begin{abstract}
In this paper, the corrosion resistance test of sisal fiber-reinforced concrete under simulated marine environment is carried out, and the corrosion resistance of sisal fiber-reinforced concrete is predicted by using grey theory and Verhulst model. The results show that sisal fiber can effectively improve the strength of concrete under the corrosion of marine environment. With the increase in sisal fiber content, the compressive strength of concrete increases as a whole compared with that of concrete without sisal fiber. After 15 days of corrosion cycle, the maximum strength increase ratio of concrete with sisal fiber is 18.58. After 30 days of corrosion cycle, the maximum strength increase ratio of concrete with sisal fiber is 12.72 . The GM $(1,1)$ model and Verhulst model in grey system theory are used to simulate the mechanical properties of sisal fiber-reinforced concrete and its corrosion resistance in marine environment. The results show that the average relative residual difference between the simulated and measured values is small and belongs to the first-order accuracy. It shows that the GM $(1,1)$ model and Verhulst model in grey system theory can be used in the mechanics of sisal fiberreinforced concrete, and prediction and analysis of performance and corrosion resistance in marine environment. A new corrosion-resistant material may be born from it.
\end{abstract}

Keywords Sisal fiber concrete $\cdot$ Mechanical property $\cdot$ Corrosive $\cdot$ Grey theory $\cdot$ Marine environment

\section{Introduction}

As early as the early twentieth century [1], the corrosion of Portland cement hydrates in seawater and groundwater was found. For more than a century, researchers have taken many technical measures to improve the corrosion of marine concrete. However, the durability of cement concrete in marine environment still exists and has become a worldwide problem [2]. Nowadays, there are many reports about corrosion accidents of cement concrete around the world. Every year, the economic losses of buildings around the world caused by the chloride salt corrosion are enormous. Hou et al. [3] statistics show that in 2014 only China's total cost of corrosion (including losses caused by corrosion and anti-corrosion inputs) accounted for about $3.34 \%$ of GDP in the year, totaling over 2.1 trillion RBM. Ke [4] found that the loss caused by the corrosion of reinforced concrete structures is about 500 billion RBA, and the corrosion loss of bridges, highways and other buildings is as high as 100 billion RBA. The investigation of the port terminal by Hohai University and other units found that nearly $90 \%$ of the port terminals that used $7-25$ years had steel corrosion damage [5]. Investigation Findings of subordinate units of Ministry of Transport of the People's Republic of China [2]. Of the 18 wharfs in the southern coast of China which have been used for 7-25 years, 16 have obvious corrosion and 9 have serious corrosion. Of the 22 wharfs in the southeast coast of China which have

Huiming Bao, bhming@163.com | 1 College of Civil Engineering and Architecture, Guilin University of Technology, Guilin 541004, China. ${ }^{2}$ China Communications Press Co., Ltd. Love Self-Driving Media, Beijing 10013, China. ${ }^{3}$ Guangxi Vocational and Technical College of Communications, Nanning 530023, China. 
been used for $8-32$ years, $55.6 \%$ of them have concrete protective layer falling off seriously. In 14 wharfs along the northern coast of China which have been used for 2-57 years, almost all of them have concrete corrosion. In addition, according to references two, the Chesapeake Bay Tunnel Bridge in the USA is composed of bridges and underwater tunnels. It crosses the Chesapeake Bay and connects the eastern coast of Virginia on the Demava Peninsula to the metropolitan area of Virginia Beach and Hampton Anchorage, Virginia. It is called "one of the seven wonders of modern world engineering." Tunnel bridge is a reinforced concrete structure, which is divided into two parts: north and south. The north part was built in 1964 and is $37 \mathrm{~km}$ long. After testing the north part in 1989, it was found that the concrete pier of the tunnel is seriously corroded. The Moju River Bridge in the Amazon region of northern Brazil, with 860 meters of pier corrosion, collapsed in April 2019 with a 200-m bridge deck by a ferry, and two cars fell into the water. It also affected the transport of agricultural products in the northern port.

However, most of the research on the corrosion of reinforced concrete structures is aimed at the corrosion of steel bars, but the concrete corrosion caused by the other important aspects of the reinforced concrete structure does not have enough attention. Therefore, the research on the influence of marine environment on the mechanical properties of concrete materials has not only important scientific value, but also broad application prospect [6]. Deng [7] also believes that further research on concrete in seawater environment is of great significance and great practical value. Therefore, in this paper, the corrosion characteristics of sisal fiber-reinforced concrete in marine environment are studied by adding corrosion-resistant sisal fiber material to concrete, and the corrosion trend is predicted by grey theory, which provides scientific basis for the development of new corrosion-resistant materials $[8,9]$.

\section{Experiment material}

\subsection{Test raw material}

(1) Cement, using Conch brand ordinary Portland cement produced in Guilin, Guangxi, with a strength rating of 42.5. The implementation standard at the time of the test was GB175-2007.

(2) Sand, the test uses medium and coarse river sand, and all performances meet the requirements of the specification.

(3) Crushed stone, using continuous grade of gravel stone, the maximum particle size is 19.0 , the mini- mum particle size is 4.75 , and the performance meets the requirements of the specification.

(4) Admixture, the water-reducing agent used in the test is TH-W5 high-efficiency water-reducing agent, mainly based on $\beta$-sulfonic acid formaldehyde condensate, compounding a variety of auxiliary materials, its performance is in line with the national standard at that time-GB8076-1997 high-efficiency water-reducing agent first-class indicators. The water consumption reduction rate is $15 \%$ measured, and the slump degree can be increased by $10-20 \mathrm{~mm}$ while ensuring that the water-cement ratio is constant.

(5) Seawater, from Beihai City, Guangxi, China

(6) Sisal fiber. The sisal fiber used in the test is made by Guangxi Jianma Group Co., Ltd., which is first cut into short fibers with a length of $1-1.2 \mathrm{~mm}$ and then immersed in $1 \% \mathrm{NaOH}$ solution for $30 \mathrm{~min}$ and dried in the oven until the water content is less than $1 \%$, and the oven temperature is adjusted to $80^{\circ} \mathrm{C}$. Sisal fiber is soaked in $\mathrm{NaOH}$ solution, mainly because sisal fiber forms a weak boundary layer with the composite material. After soaking in $\mathrm{NaOH}$ solution, it can dissolve some pectin and vegetable lipids and reduce impurities in sisal fiber. The content, the hemicellulose is extracted, so that the specific gravity of the cellulose in the sisal fiber is increased, and the crystallinity of the fiber as a whole is also increased.

\subsection{Production and maintenance of concrete test blocks}

The test pieces for the physical and mechanical properties and durability of concrete were tested in groups of three. In the physical and mechanical properties test, the compression test piece is $150 \times 150 \times 150 \mathrm{~mm}$, and the anti-fold test piece is $150 \times 150 \times 550 \mathrm{~mm}$. The test mixture used in each test piece and its corresponding comparative test piece should be taken out from the concrete mixed with the same dish according to different requirements. When making concrete test blocks, the amount of materials should be based on the weight. The weighing accuracy should be: $\pm 0.5 \%$ for cement, water and water-reducing agent; $\pm 1 \%$ for aggregate. All test pieces should be made immediately after the concrete is mixed. The test piece used for the test piece is made of cast iron, which has sufficient rigidity and is easy to assemble and disassemble. The inner surface unevenness of the test mold does not exceed $0.05 \mathrm{~mm}$ per $100 \mathrm{~mm}$, and the non-perpendicularity of each adjacent surface after assembly does not exceed $0.5^{\circ}$. The test mold was cleaned and coated with a release agent before making the test piece [8]. The production process of each case is as follows: 
For concrete without sisal content, since the slump is more than $25 \mathrm{~mm}$ and less than $70 \mathrm{~mm}$, the test sample needs to be vibrated and formed with standard vibration table. During the vibration forming of the vibration table, the concrete mixture shall be put into the test mold once and higher than the upper mouth of the test mold. During the loading, the spatula shall be used to slightly insert and vibrate along the inner wall of the test mold. When loading, use a spatula to insert the mold along the inner wall of the test mold. To prevent the test pattern from jumping freely on the vibration table during vibration, fix the test mold with a shovel or other object. The vibration continues until the emulsion cement slurry appears on the concrete surface. When the concrete is added at any time during vibration, the test mold is always full, the vibration time is recorded, the excess concrete is scraped off after the vibration, and the surface is leveled with the spatula. It must not exceed $0.5 \mathrm{~mm}$. The vibrating table has a vibration frequency of $50 \pm 3 \mathrm{~Hz}$ and an amplitude of $0.5 \mathrm{~mm}$ at no load.

The concrete with sisal fiber content is $2.0 \mathrm{~kg} / \mathrm{m}^{3}, 3.0 \mathrm{~kg} /$ $\mathrm{m}^{3}, 4.5 \mathrm{~kg} / \mathrm{m}^{3}$ and $6.0 \mathrm{~kg} / \mathrm{m}^{3}$, its slump is less than $25 \mathrm{~mm}$, so the test sample needs to be made by the vibration of the inserting vibrating rod with a diameter of $25 \mathrm{~mm}$. The concrete is loaded into the test mold at one time, concrete mixture is raised above the test die, and the trowel is inserted along the wall of the test mold by charging. When vibrating, the vibrating bar should not touch the bottom plate of the test die, and the distance from the bottom plate is $10-20 \mathrm{~mm}$. It vibrates until the surface is pulverized. In order to prevent the segregation of concrete, overvibration should be avoided. The general vibrating time is $20 \mathrm{~s}$. The vibrating rod should be pulled out slowly and should not leave holes. A scraper is used to scrape off the excess concrete, and it is smoothed with a spatula. The difference between the test piece surface and the edge of the test die should not exceed $0.5 \mathrm{~mm}$. After standing for 1-2 days and nights, the concrete test block is demolished and numbered and then placed in a non-flowing water of $20 \pm 3{ }^{\circ} \mathrm{C}$ for maintenance to the required age. The $\mathrm{pH}$ of the water is not less than 7 .

\section{Test result and mechanism analysis}

\subsection{Test result}

Under the corrosion of seawater, after a certain number of cycles of alternating hot drying and cold drying, the compressive strength of sisal fiber concrete is shown in Table 1 and Fig. 1.

As can be seen from Fig. 1, in the case of seawater corrosion, after a certain number of dry and wet cycles, the compressive strength of sisal fiber concrete is significantly reduced compared with the specimens cured in the 28-day-old curing pond, and with the dry cycle as the number of wet cycles increases, the intensity decreases. After 15 days of hot and cold alternating wet and dry cycles, the concrete without sisal fiber had the largest decrease in strength compared with the 28-day-old test piece, and the reduction ratio was $16.01 \%$. After 30 days of hot and dry alternating wet and dry cycles, the strength of the fiber concrete with a sisal content of $6.0 \mathrm{~kg} / \mathrm{m}^{3}$ decreased the most, with a reduction ratio of $23.3 \%$. This shows that after seawater corrosion, both ordinary concrete and sisal fiber concrete are less than the strength of the 28-day standard test piece.

It can also be found that from the change curve of compressive strength of sisal fiber concrete, it can be seen that

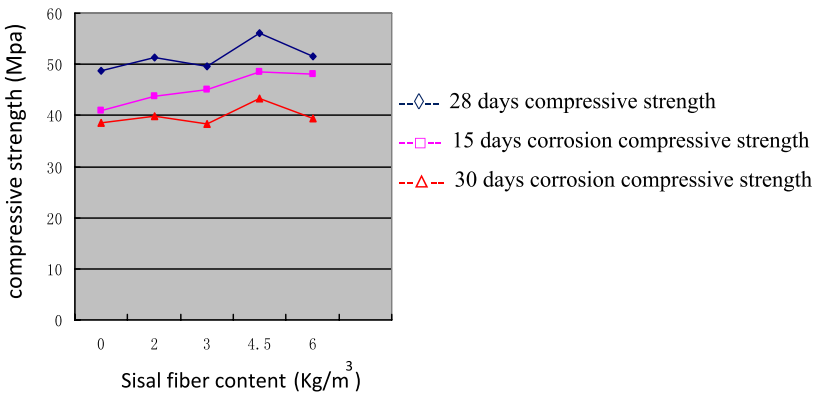

Fig. 1 Corrosion intensity curve of sisal fiber concrete in marine environment

Table 1 Concrete compressive strength after alternating hot and cold drying cycles

\begin{tabular}{lllllll}
\hline Sisal content & $\begin{array}{l}\text { 28-day compressive } \\
\text { strength (MPa) }\end{array}$ & $\begin{array}{l}\text { Strength } \\
\text { increase (\%) }\end{array}$ & $\begin{array}{l}\text { 15-day corrosion com- } \\
\text { pressive strength (MPa) }\end{array}$ & $\begin{array}{l}\text { Strength } \\
\text { increase (\%) }\end{array}$ & $\begin{array}{l}\text { 30-day corrosion com- } \\
\text { pressive strength (MPa) }\end{array}$ & $\begin{array}{l}\text { Strength } \\
\text { increase } \\
(\%)\end{array}$ \\
\hline 0 & 48.7 & 100 & 40.9 & 100 & 38.5 & 100 \\
2 & 51.3 & 105.34 & 43.8 & 107.1 & 39.8 & 103.38 \\
3 & 49.6 & 101.85 & 45.1 & 110.27 & 38.3 & 99.48 \\
4.5 & 56.2 & 115.4 & 48.5 & 118.58 & 43.4 & 112.73 \\
6 & 51.5 & 105.75 & 48.1 & 117.6 & 39.5 & 102.6 \\
\hline
\end{tabular}


the corrosion strength of concrete is significantly lower than that of the 28-day-old specimen after 15 days of seawater corrosion. However, the strength of concrete with sisal fiber increases with the increase in sisal content compared with concrete without sisal fiber that corroded under the same conditions. When the sisal content is $4.5 \mathrm{~kg} / \mathrm{m}^{3}$, the largest increase ratio is $18.58 \%$. From the compressive strength of concrete after 30 days of seawater corrosion, it can be seen that the strength of most concrete with sisal fiber is higher than that of concrete without sisal fiber, and the maximum increase is $12.72 \%$. This shows that the addition of sisal fiber cannot completely prevent the corrosion of concrete in marine environment, but it can effectively slow down the corrosion rate and prolong the service life of concrete.

Figure 1 also shows that in the 15th and 30th hot and cold alternating wet and dry cycle tests, when the sisal content is $3.0 \mathrm{~kg} / \mathrm{m}^{3}$, the curve of the strength increasing with the increase in sisal has a certain degree. The lower fold indicates that the increase is slower. The content of sisal fiber is increased continuously. When the content is $4.5 \mathrm{~kg} / \mathrm{m}^{3}$, the compressive strength of concrete under the same condition corrosion is greatly increased compared with the concrete without sisal fiber and reaches the maximum value. This shows that in the case of marine environmental corrosion, with the increase in the amount of sisal fiber, the compressive strength of concrete generally increases compared with the concrete without sisal fiber.

\subsection{Analysis of corrosion mechanism}

The incorporation of sisal fiber can effectively slow down the corrosion rate of concrete in the marine environment. The main reason is that sisal fiber will run up under seawater soaking, which is effective for less shrinkage cracks of concrete and sisal fiber under pressure. It has the effect of preventing the development of fine cracks. Under the action of alternating hot and cold cycles, the concrete is first immersed in the seawater solution. At this time, due to the water absorption of the sisal fiber, a certain pressure is generated in the concrete test block before putting the test block into the test block. When drying in the oven, this part of the pressure offsets the shrinkage crack caused by the concrete under high temperature. Therefore, with the increase in the lower content of sisal, the offset effect is gradually strengthened, and the shrinkage crack generated by the concrete is also greatly increased. Due to the decrease of cracks, the invasion of corrosive medium is further reduced under the condition of seawater immersion, thus the corrosion rate of concrete is reduced. In addition, when the concrete test block is under pressure, the effect of sisal fiber on preventing the development of longitudinal fine cracks is still very obvious, which further prevents the concrete from cracking, thereby increasing the strength of the concrete. Therefore, the incorporation of sisal fiber can effectively improve the corrosion resistance of concrete in the marine environment.

\section{Grey prediction of corrosion performance of sisal fiber concrete}

\subsection{The corrosion resistance characteristics of sisal fiber-reinforced concrete}

Concrete buildings such as cement pavements have long been in the marine environment due to the influence of seawater, sea breeze and erosive media in sea fog, which often fail to meet the design service life and cause serious damage. Through experimental research, it is found that although the incorporation of sisal fiber cannot completely prevent the corrosion of concrete in the marine environment, it can effectively reduce the corrosion rate and prolong the service life of concrete. From the test results (see Table 1), it can be seen that after 15 days of corrosion cycle, the concrete with sisal fiber is increased by $18.58 \mathrm{c} / \mathrm{o}$ than the concrete without sisal fiber; after 30 days of corrosion cycle, it is mixed. The concrete with sisal fiber has a maximum strength increase of $12.72 \mathrm{c} / \mathrm{o}$ compared to the concrete without sisal fiber. This is because the swelling effect of sisal fiber can effectively reduce the shrinkage crack of concrete and further reduce the intrusion of corrosive medium, and under the pressure state, the effect of sisal fiber to prevent crack development is still very obvious. The results show that the incorporation of sisal fiber can effectively reduce the corrosion rate of concrete in the marine environment and is beneficial to its corrosion resistance in the marine environment.

\subsection{Simulation of corrosion resistance of sisal fiber concrete with GM $(1,1)$ model and Verhulst model}

Using the same method, the GM $(1,1)$ model and the Verhulst model were used to calculate the 28 flexural strength, 15-day corrosion compressive strength and 30-day corrosion compressive strength for comparison and analysis, as shown in Tables 2, 3, 4 and 5 and Figs. 2, 3, 4 and 5.

It can be seen from the fitting results in Tables 2, 3, 4 and 5 and Figs. 2, 3, 4 and 5 that the predicted results of the GM $(1,1)$ model and the Verhulst model are basically consistent with the actual values, and the average relative residual obtained by the prediction accuracy test belongs to the first level. The accuracy (good) indicates that the fitting value of the model fitting value and the measured value are highly accurate, and the $\mathrm{GM}(1,1)$ model and 
Table 2 28-day compressive strength simulation

\begin{tabular}{lcc}
\hline Measured value & $\begin{array}{l}\text { GM }(1,1) \text { fitted } \\
\text { value }\end{array}$ & $\begin{array}{l}\text { Verhulst } \\
\text { fitted } \\
\text { value }\end{array}$ \\
\hline 41.81 & 41.8100 & 41.8100 \\
45.6 & 44.7624 & 44.2648 \\
44.51 & 45.4578 & 45.7314 \\
45.6 & 46.1640 & 46.5742 \\
47.56 & 46.8812 & 47.0478 \\
Average relative residual & $1.33 \%$ & $0.60 \%$ \\
\hline
\end{tabular}

Table 3 28-day flexural strength

\begin{tabular}{lll}
\hline Measured value & $\begin{array}{l}\text { GM }(1,1) \text { fitted } \\
\text { value }\end{array}$ & $\begin{array}{l}\text { Verhulst } \\
\text { fitted } \\
\text { value }\end{array}$ \\
\hline 6.3 & 6.3000 & 6.3000 \\
6.52 & 6.3828 & 6.3106 \\
6.23 & 6.3909 & 6.3317 \\
6.31 & 6.3991 & 6.3744 \\
6.52 & 6.4072 & 6.4614 \\
Average relative residual & $1.57 \%$ & $0.66 \%$ \\
\hline
\end{tabular}

Table 4 15-day corrosion compressive strength

\begin{tabular}{lcc}
\hline Measured value & $\begin{array}{l}\text { GM }(1,1) \text { fitted } \\
\text { value }\end{array}$ & $\begin{array}{l}\text { Verhulst } \\
\text { fitted } \\
\text { value }\end{array}$ \\
\hline 40.9 & 40.9000 & 40.9000 \\
43.8 & 43.9734 & 43.7406 \\
45.1 & 45.5342 & 45.8051 \\
48.5 & 47.1505 & 47.2525 \\
48.1 & 48.8241 & 48.2417 \\
Average relative residual & $1.13 \%$ & $0.51 \%$ \\
\hline
\end{tabular}

Table 5 30-day corrosion compressive strength

\begin{tabular}{lcc}
\hline Measured value & $\begin{array}{l}\text { GM }(1,1) \text { fitted } \\
\text { value }\end{array}$ & $\begin{array}{l}\text { Verhulst } \\
\text { fitted } \\
\text { value }\end{array}$ \\
\hline 38.5 & 38.5000 & 38.5000 \\
39.8 & 39.6294 & 39.1201 \\
38.3 & 40.0401 & 39.5925 \\
43.4 & 40.4550 & 39.9497 \\
39.5 & 40.8743 & 40.2185 \\
Average relative residual & $3.05 \%$ & $1.05 \%$ \\
\hline
\end{tabular}

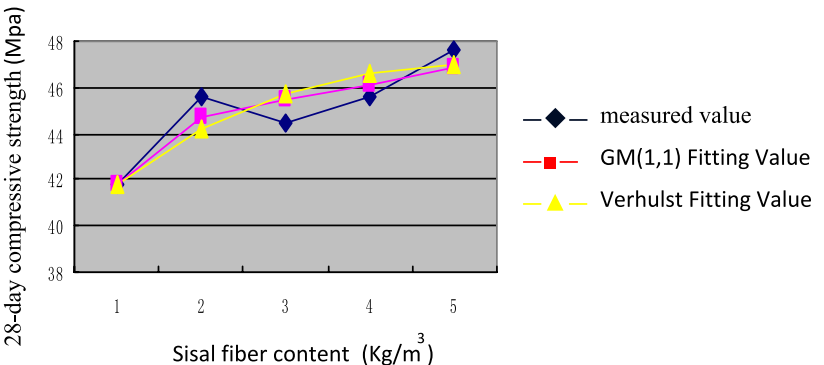

Fig. 2 28-day compressive strength different model fitting comparison chart

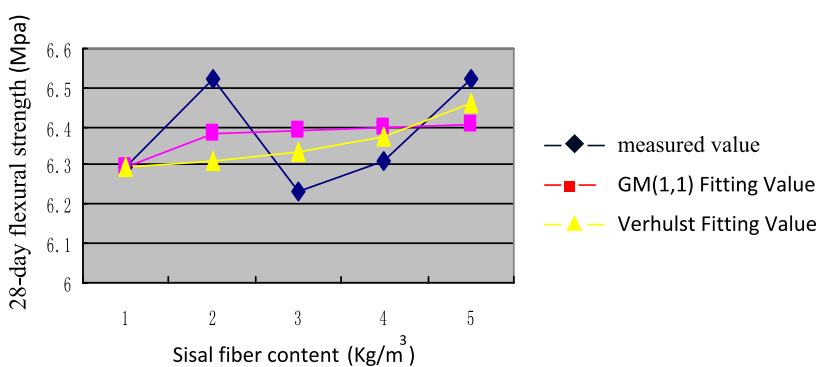

Fig. 3 Fitting contrast charts of 28-day flexural strength with different models

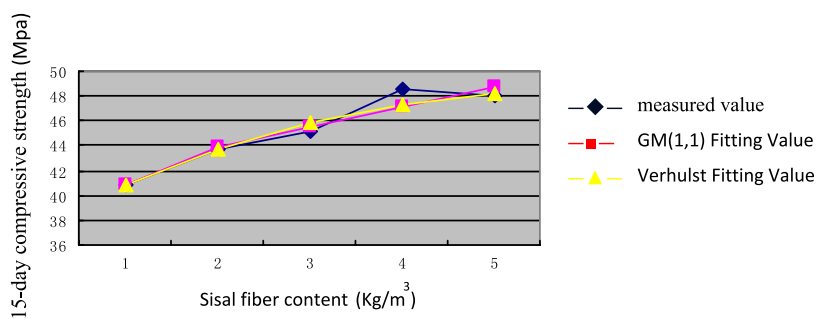

Fig. 4 15-day corrosion resistance strength different model fitting comparison chart

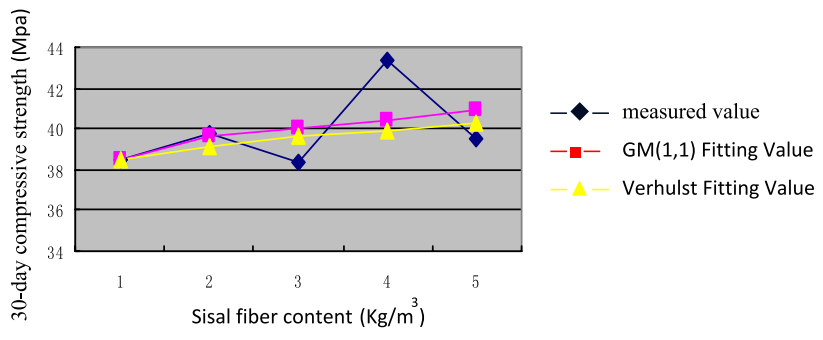

Fig. 5 30-day corrosion compressive strength different model fitting comparison chart 
the Verhulst model can be used for the later prediction analysis.

\section{Conclusion}

(1) In the case of marine environmental corrosion, sisal fiber can effectively improve concrete strength. With the increase in sisal fiber content, the compressive strength of concrete generally increases compared with concrete without sisal fiber.

(2) It can be seen from the variation curve of the intensity with the amount of sisal. At $3.0 \mathrm{~kg} / \mathrm{Ma}$, the strength curve has different degrees of lower fold. Later, as the sisal content continues to increase, the strength is greatly improved. It can be seen from the trend of the curve that the intensity increases with the increase in the amount of sisal.

(3) After 15 days of corrosion cycle, the concrete with sisal fiber is increased by $18.58 \mathrm{c} / \mathrm{o}$ than the concrete without sisal fiber; after 30 days of corrosion cycle, the concrete mixed with sisal fiber is more than unmixed one. The maximum increase in concrete strength of sisal fiber is $12.72 \mathrm{c} / \mathrm{o}$.

(4) Sisal fibers swell in seawater to reduce shrinkage cracks of concrete. Sisal fibers can prevent the development of microcracks under pressure. Therefore, the corrosion rate of concrete in marine environment can be effectively slowed down and the service life of concrete can be prolonged.

(5) The GM $(1,1)$ model and the Verhulst model in the grey system theory simulate the mechanical properties of sisal fiber concrete and its corrosion resistance in the marine environment. The average relative residuals of the simulated and measured values are found. Both are small and belong to the first-order precision, indicating that the $\mathrm{GM}(1,1)$ model and the
Verhulst model in the grey system theory can be used for the predictive analysis of the mechanical properties of sisal fiber concrete and the corrosion resistance under the marine environment.

Acknowledgements The paper is provided by National Natural Science Foundation of China (Project No.: 51768016).

\section{Compliance with ethical standards}

Conflict of interest The authors declare that they have no conflict of interest.

\section{References}

1. Proceedings of the American Society of Civil Engineers (1975) J Struct Div Cl-Premier PTE LTD

2. Wang $Y$ (2019) Important mission of cement industry in contemporary china: solving the problem of seawater corrosion resistance of cement. China Build Mater Newsp 001:1-4

3. Hou B et al (2017) Corrosion cost in China. Science Press, Beijing

4. Ke W (2003) China corrosion investigation report. Chemical Industry Press, Beijing

5. Zhang P, Xian Y (2005) Rebar corrosion and protection of concrete structures in coastal areas. Coast Eng 24(2):78-84

6. Chen D, Dong P, Liao Y (2007) Retrospect and prospect of mechanical study of corrosion in marine concrete. Corros Prot 28(12):630-632

7. Deng S (2018) Current situation and prospects of study on concrete in seawater environment in China. J Qinzhou Univ 33(8):1-8

8. Bao H, Qin F, Yu W, You W (2008). Test study the properties of the sisal fiber concrete. Yangtze River 39(13):88-90, 104

9. Bao H, Meng H (2011) Study of sisal fiber concrete mechanical properties. Concrete 257(3):63-66

Publisher's Note Springer Nature remains neutral with regard to jurisdictional claims in published maps and institutional affiliations. 